\title{
Conf $-950444--2$
}

SAND95-0345C

\section{HEALTH MONITORING OF OPERATIONAL STRUCTURES - INITIAL RESULTS}

\author{
George James, Randy Mayes, Thomas Carne \\ Experimental Structural Dynamics Department \\ Sandia National Laboratories \\ Albuquerque, NM 87185-0557 \\ Todd Simmermacher \\ University of Houston \\ James Goodding \\ CSA Engineering, Inc.
}

\begin{abstract}
Two techniques for damage localization (Structural Translational and Rotational Error Checking STRECH and MAtriX COmpletioN - MAXCON) are described and applied to operational structures. The structures include a Horizontal Axis Wind Turbine (HAWT) blade undergoing a fatigue test and a highway bridge undergoing an induced damage test. STRECH is seen to provide a global damage indicator to assess the global damage state of a structure. STRECH is also seen to provide damage localization for static flexibility shapes or the first mode of simple structures. MAXON is a robust damage localization tool using the higher order dynamics of a structure. Several options are available to allow the procedure to be tailored to a variety of structures.
\end{abstract}

\section{INTRODUCTION}

Today's society depends upon many structures (such as aircraft, bridges, wind turbines, offshore platforms, and buildings) which are nearing the end of their design lifetime. Since many of these structures cannot be economically replaced, techniques for damage detection and health monitoring must be developed and implemented. Modal and structural dynamics measurements hold promise for the global non-destructive inspection of a variety of structures since surface measurements of a vibrating structure can provide information about the health of the internal members without costly (or impossible) dismantling of the structure. Advanced signal processing, noncontacting and embedded sensors, and analysis/test correlation technologies combine to make this a promising approach for the health monitoring of operational structures.

An operational structure is defined to be one which can perform, is performing, or has performed its intended function as opposed to a laboratory test article or a computer model. Operational structures are often geometrically complex and may be too large to test in a laboratory. These structures are rarely truss-like and in fact tend to be more plate-like. Also, the boundary conditions associated with such structures are not known as well as a laboratory test structure or a computer model. And finally, the environment associated with an operational structure (e.g. weather, traffic patterns, or location) is usually changing and has a serious impact on the measured structural response. Therefore, it is desirable to perform health monitoring research and development on structures possessing such characteristics. This work discusses damage detection studies using three different operational structures.

Three bodies of research have been instrumental in the development of a health monitoring capability at Sandia National Laboratories. The work of Zimmerman, Simmermacher, and others at the University of Houston [1-7 ]; the research team at the University of Colorado at Boulder (Alvin, Doebling, Park, and Peterson) [8-13]; and Mayes, James, Hansche and others at Sandia National Laboratories 
[14-18]. The work presented herein draws heavily off these works.

The paper begins by describing the approach used to locate damage. A technique (Structural Translation and Rotation Error CHecking algorithm or STRECH) used for damage localization and calculating a global damage indicator is described [18 ]. Another new technique (MAtriX COmpletioN or MAXCON) for damage localization which is an extension of Zimmerman's [7] and the UC-Boulder [12] work is then described. These techniques are applied to two data sets including a fatigue test of a wind turbine blade and a bridge undergoing an induced damage test [19].

\section{STRECH}

STRECH originated as a static concept to locate soft or stiff areas of a finite element model by comparing the lowest cantilevered mode shapes from a modal test with the Finite Element Model (FEM). A description of the algorithm utilizing static displacements from a two degree of freedom system has been provided in reference [18]. Although this concept is a static one, success has been realized by application to the first cantilevered mode shape when the mode shape looks a great deal like the static displacement shape [14] or to static flexibility shapes as estimated from dynamic mode shapes [18]. STRECH has been utilized for FEM error localization on a cantilevered robot arm, a cantilevered missile payload, and a cantilevered third stage of a missile with payload. In each case significant stiffness differences between a finite element model and a modal test mode shape were identified, enabling the analyst to identify critical parameters to update in the finite element model. STRECH has been extended to perform damage detection using experimental results before and after damage has occurred [18]. In this mode, STRECH has been applied to highway bridge [18], a simulated aircraft panel [20], and to a cantilevered wind turbine blade, as will be reported herein.

The user of STRECH defines a series of load paths which connect the sensor locations of the structure under test in a physically meaningful sense. This usually entails linking a sensor to its nearest neighbors. The STRECH Ratio (SR) between two sensors (denoted by subscripts $\mathbf{i}$ and $\mathbf{j}$ ) is calculated as follows:
$\mathrm{SR}_{\mathrm{ij}}=\frac{\mathrm{x}_{\mathrm{ij}}^{\mathrm{d}}}{\mathrm{x}_{\mathrm{ij}}} \cdot \frac{\sum_{\mathrm{kl}} \mathrm{x}_{\mathrm{kl}}}{\sum_{\mathrm{kl}} \mathrm{x}_{\mathrm{kl}}^{\mathrm{d} l}}$,

where xij are measured relative displacements.

The superscript ${ }^{d}$ indicates data from the potentially damaged state. Data with no superscript is the baseline data which is considered undamaged. The summations are for all displacement differences defined along the load paths by the engineer. This basically defines the displacement difference $x_{i j}$ as a fraction of the sum of all displacement differences measured for the structure's specific state. This normalization has been applied to handle problems such as global scaling errors which often occur in acquiring and fitting experimental data.

Although the average SR is not always exactly equal to one, it is generally very near one. This makes the interpretation of the data much easier, as a value much greater than one will indicate an area of the structure that has been significantly reduced in stiffness (i.e. damaged). The highest SR should correspond to the part of the structure most likely to be damaged. In practice, $x$ is usually a displacement difference between two points on the structure, each of which has three coordinates. The algorithm calculates the square root of the sum of the squares of the three coordinate displacement differences, so that all $x$ quantities shown in equation 1 are positive values. In many applications, not all accelerations are measured, however the accelerations in unmeasured coordinate directions are considered zero.

From equation 1 it can be seen that if $\mathrm{x}_{\mathrm{ij}}$ is very small, the SR can become very uncertain. Since all experimental data has noise associated with it, and data fitting algorithms are not perfect either, a false SR that is very large (because of a small denominator corrupted significantly by noise) may be calculated. A small value of $\mathrm{x}_{\mathrm{ij}}$ in the denominator means that the structure is not being exercised between points $i$ and $j$ in the baseline structure. If this is the case, the true response should be insensitive to damage between those two points. Therefore, the engineer establishes a minimum denominator value for $\mathrm{x}_{\mathrm{ij}}$ below which the $\mathrm{SR}$ is not calculated at all. In the algorithm, the minimum denominator value is set as a percentage of the largest displacement difference for the baseline structure. 


\section{DISCLAIMER}

This report was prepared as an account of work sponsored by an agency of the United States Government. Neither the United States Government nor any agency thereof, nor any of their employees, makes any warranty, express or implied, or assumes any legal liability or responsibility for the accuracy, completeness, or usefulness of any information, apparatus, product, or process disclosed, or represents that its use would not infringe privately owned rights. Reference herein to any specific commercial product, process, or service by trade name, trademark, manufacturer, or otherwise does not necessarily constitute or imply its endorsement, recommendation, or favoring by the United States Government or any agency thereof. The views and opinions of authors expressed herein do not necessarily state or reflect those of the United States Government or any agency thereof. 


\section{DISCLAIMER}

Portions of this document may be illegible in electronic image products. Images are produced from the best available original document. 
Experience has shown that SRs based on differences in rotational coordinates can provide more information than those based on translational coordinates. Field measurements are most often measured accelerations in the translational directions. Estimates of the rotations can be obtained from displacement shape data by passing a parabola through three adjacent displacements on the structure. The slope of the parabola at the middle point can be utilized as the estimate for the rotation of that point.

In some applications, SR calculations are more successful in detecting the location of damage when applied to a static deflection shape. An estimate of the static flexibility (the static deflection shape due to a unit load) can be obtained from the modal parameters by use of the following well known formula for the frequency response function based on real modes:

$$
\frac{x(\omega)}{f(\omega)}=\sum_{r=1}^{\infty} \frac{\Psi_{i}^{r} \Psi_{k}^{r}}{m_{r}\left(\omega_{r}^{2}-\omega^{2}+2 j \zeta_{r} \omega \omega_{r}\right)}
$$

where $x(\omega)$ is displacement as a function of frequency, $f(\omega)$ is an applied point force as a function of frequency, $\Psi_{i}^{r}$ is the mode shape at the response point for the $r$ th mode, $\Psi_{k}^{r}$ is the mode shape at the driving point for the $r$ th mode, $m_{r}$ is the modal mass, $\zeta_{r}$ is the damping ratio, $\omega$ is the frequency in radians/second, $\omega_{r}$ is the $r$ th natural frequency and the summation is for all modes. An estimate of the static flexibility is achieved by evaluating equation 2 at zero frequency. In this case a truncation is made using only $\mathrm{n}$ modes:

$$
\frac{x(0)}{f(0)}=\sum_{r=1}^{n} \frac{\Psi_{i}^{r} \Psi_{k}^{r}}{m_{r} \omega_{r}^{2}}
$$

It should be noted that the engineer is free to chose any measured output location as the input location for these calculations. The SR calculated with damage location as the input has the greatest sensitivity to damage. Unfortunately, this location will not be known a priori in real applications.

Displacement differences can be combined to calculate a global damage indicator for the onset of recognizable damage. A threshold value for that quantity needs to be established which is high enough to discount the effects of noise, but low enough to sense significant damage. A quantity which has been developed to perform this function:
Damage Indicator $(D I)=\frac{\sum_{i j}\left|x_{i j}-x_{i j}^{d}\right|}{\sum_{i j} x_{i j}}$

where the terminology is the same as in equation (1). A procedure for establishing a noise floor for the damage indicator has been to extract the modal parameters two or more times using different extraction methods. The damage indicator variation calculated from these cases can provide an indication of the noise level to be expected.

The following sections details another damage detection approach which estimates mass and stiffness matrices directly from data and uses that representation to localize changes in the structure from subsequent tests.

\section{MAXCON}

Zimmerman's approach to damage detection involves using modal frequencies $\left(\omega_{\mathrm{T}}{ }^{\mathrm{d}}\right)$ and massnormalized mode shapes $\left(\Psi_{r}^{d}\right)$ measured on the damaged structure as well as undamaged mass and stiffness matrices (M and $\mathrm{K}$ - typically from a FEM reduced to the test degrees of freedom or some intermediate value) $[6,7]$. An error vector $B_{r}$ can be calculated for each mode and subsequently collected in matrix form:

$$
B=-M \Psi^{d} \omega^{d^{2}}+K \Psi^{d}=\left[\begin{array}{l:l:l:l}
B_{1} & B_{2} & \cdots & B_{n}
\end{array}\right]
$$

where all of the above quantities are matrix quantities containing information from all of the measured modes. The matrix $\omega^{2}$ is a diagonal matrix with the squares of the modal frequencies from the damaged test on the diagonal. Note that $B$ would be a matrix of zeros if the undamaged modal properties are used. In theory, the zero/non zero pattern of the dynamic residual, $B$, will provide the information as to the location of the damage when damaged modal properties are used. In actuality, noise and modeling issues will corrupt this zcro/non zero pattern. Also, FEM reduction procedures will tend to mask the true location of the errors $[6,7]$.

Also, areas of the structure which are very stiff will tend magnify noise measurements in the data and provide false indications of damage. Therefore, a scaling can be performed to reduce this effect: 


$$
\hat{B}_{r}=W_{r} B_{r} /\left\|\Psi_{r}^{d}\right\|
$$

where

$$
\begin{aligned}
& \mathrm{W}_{\mathrm{r}}=\operatorname{diag}\left(\frac{1}{\left\|\mathrm{z}_{1}\right\|}, \frac{1}{\left\|\mathrm{z}_{2}\right\|}, \ldots, \frac{1}{\left\|\mathrm{z}_{\mathrm{n}}\right\|}\right) ; \text { and } \\
& Z_{s}=\left[\begin{array}{c}
\frac{z_{r}^{1}}{z_{r}^{2}} \\
\hline \vdots \\
\frac{z_{r}^{n}}{n}
\end{array}\right]=-M \omega_{r}^{d^{2}}+K
\end{aligned}
$$

Analyzing the dynamic residual matrix, $\mathrm{B}$, to determine the damage locations can be difficult. However, the most important information can be extracted by performing a Singular Value Decomposition (SVD) on the matrix and viewing the first left singular vector.

To avoid the problems associated with reducing a FEM to the test degree's of freedom, this work uses mass and stiffness matrices which are calculated from data as Alvin, Peterson, Park, and Doebling have done $[11,12]$. The inverses of these matrices can be thought of as sums of the measured parameters:

$$
\begin{aligned}
& \mathrm{M}^{-1}=\Psi \Psi^{\mathrm{T}} ; \text { and } \\
& \mathrm{K}^{-1}=\Psi \omega^{-2} \Psi^{\mathrm{T}} .
\end{aligned}
$$

If the test data contains as many modes as sensor locations then these matrices could be inverted directly. However, the typical situation in testing is to acquire data from many more sensor locations than the number of extracted modes. Therefore the inverse matrices are rank deficient and not invertable. A pseudo-inverse can be used to calculate rank-deficient mass and stiffness matrices [12]. Another approach is to augment the measured mode shapes with the null space of the rank-deficient $\mathrm{M}^{-1}$ matrix similar to the approach used in reference [11]. The null space $\left(U^{N}\right)$ of this matrix can be calculated using the SVD:

$$
M^{-1}=\left[\begin{array}{l:l}
U^{R} & U^{N}
\end{array}\right]\left[\begin{array}{cc}
\operatorname{diag}(S) & 0 \\
0 & \operatorname{diag}(0)
\end{array}\right]\left[\begin{array}{l}
U^{R^{T}} \\
\hdashline U^{N^{T}}
\end{array}\right] .
$$

The null space will be scaled by replacing diag $(0)$ with a diagonal matrix of non-negative entries, denoted by $\operatorname{diag}\left(X^{-1}\right)$, chosen to have the final mass matrix $M$ meet some prearranged criteria. The final mass matrix will then have the following form:

$$
\mathrm{M}=\left[\begin{array}{l:l}
\mathrm{U}^{\mathrm{R}} & \mathrm{U}^{\mathrm{N}}
\end{array}\right]\left[\begin{array}{cc}
\operatorname{diag}\left(\mathrm{S}^{-1}\right) & 0 \\
0 & \operatorname{diag}(\mathrm{X})
\end{array}\right]\left[\begin{array}{c}
\mathrm{U}^{\mathrm{R}^{\mathrm{T}}} \\
\hdashline \mathrm{U}^{\mathrm{N}^{\mathrm{T}}}
\end{array}\right]
$$

This then allows the matrix to be completed (hence the acronym MAXCON) in spite of the rankdeficiency. The criterion used in this work is to attempt to force certain elements of $M$ to be zero to reflect an assumed model of the structure. This requires the user to select load paths similar to that done for the STRECH algorithm. The work reported herein assumes springs are connecting each sensor to its nearest neighbor as well as additional springs to ground. This allows the elements of $X$ to be chosen in a least squares sense to drive the required elements of $\mathrm{M}$ toward zero. It should be noted that the problem must be constrained if any elements of $X$ are less than zero. The problem as posed above will not produce any zeros in the mass matrix as there is noise in the measurements and the simple underlying model will not usually capture the dynamics of the full system. Also, no attempt has been made in this work to constrain the selection of the values in $X$ to match any other known quantities such as total mass or total inertia of the system. Adding such constraints should be included in future research.

The stiffness matrix is then calculated from the mass matrix as follows:

$$
\begin{aligned}
& \mathrm{K}=\mathrm{M} \Psi \omega^{2} \Psi^{\mathrm{T}} \mathrm{M}+ \\
& M U^{\mathrm{N}} \operatorname{diag}\left(X^{1 / 2}\right) \operatorname{diag}(\mathrm{Y}) \operatorname{diag}\left(X^{1 / 2}\right) U^{\mathrm{N}^{\mathrm{T}}} \mathrm{M}
\end{aligned}
$$

where $\operatorname{diag}(\mathrm{Y})$ is chosen to reduce the elements of $\mathrm{K}$ which are expected to be zero based on the load paths chosen by the engineer. This calculation is complicated by the fact that the elements in $\mathrm{Y}$ must be larger that all the elements in $\omega^{2}$ to avoid the completion procedure placing unrealistic modes in the measured frequency band. Therefore additional inequality constraints are required. As with the mass matrix completion, no attempt has been made in this work to constrain the elements of $Y$ to reproduce the 
measured stiffness residual terms [21]. This physical constraint should also be added to the procedure.

Since a mass and stiffness representation of the structure can be provided for each damage case tested, equation (5) can be rewritten as follows:

$$
B=-\Delta M \Psi^{d} \omega^{d^{2}}+\Delta K \Psi^{d}=B_{M} \omega^{d^{2}}+B_{K}
$$

where $\Delta \mathrm{M}$ and $\Delta \mathrm{K}$ are perturbation matrices formed by differencing the respective matrices before and after damage.

Therefore, if the matrices capture enough of the major dynamics of the system, an indication of whether a mass or a stiffness change occurred may be possible.

Additionally, since a simple underlying model of the structure has been assumed, a "disassembly" may be performed to further understand the source of the changes in the system [22]. Therefore, the mass and stiffness matrices may be written in the following expanded form:

$$
\begin{aligned}
& \mathrm{M}=\mathrm{C}^{\mathrm{T}} \mathrm{M}_{\mathrm{e}} \mathrm{C}=\mathrm{C}_{1}^{\mathrm{T}} \mathrm{M}_{\mathrm{el}} \mathrm{C}_{1}+\mathrm{C}_{2}^{\mathrm{T}} \mathrm{M}_{\mathrm{el}} \mathrm{C}_{2} ; \text { and } \\
& \mathrm{K}=\mathrm{C}^{\mathrm{T}} \mathrm{K}_{\mathrm{e}} \mathrm{C}=\mathrm{C}_{1}^{\mathrm{T}} \mathrm{K}_{\mathrm{el}} \mathrm{C}_{1}+\mathrm{C}_{2}^{\mathrm{T}} \mathrm{K}_{\mathrm{el}} \mathrm{C}_{2}
\end{aligned}
$$

where $C$ is a connectivity matrix of 1 's and 0 's, $\mathrm{M}_{e}$ and $\mathrm{K}_{\mathrm{e}}$ are block diagonal matrices of the local mass and stiffness elements, $M_{e l}$ and $K_{e l}$ are matrices containing only the elements associated with the assumed simple model of the structure, $\mathrm{M}_{\mathrm{e} 2}$ and $\mathrm{K}_{\mathrm{e} 2}$ are matrices containing only the additional elements modeling the load paths that are not contained in the simple model, and $C_{1}$ and $C_{2}$ are the connectivity matrices for the corresponding submatrices.

With this separation, the B matrix can be written as the sum of a part that is due to changes in the simple model of desired load paths and a part due to changes in the extra load paths. This can be very useful, especially when the model errors are pronounced. It should be noted that no attempt has been made to assure that all of the resulting spring elements represented in $\mathrm{M}_{e}$ and $\mathrm{K}_{e}$ have a physically realizable spring constant, although the bulk of the elements are signed correctly. This is an additional constraint which could be applied to the problem.

The following section applies STRECH and MAXCON to a fatigue test of a Horizontal Axis Wind Turbine (HAWT) Blade.

\section{HAWT BLADE FATIGUE TEST}

A fatigue test to failure of a composite wind turbine blade was performed at the National Renewable Energy Laboratory. Periodic modal tests were performed during this test as well as acoustic emissions tests. This data will be utilized to further study the application of health monitoring techniques. When coupled with a non-contact transducer such as a scanning laser vibrometer, this technology could be applied in the field to periodically monitor a field of wind turbines and estimate remaining life in the blades.

\section{Description of Test}

The blade was constructed of fiberglass and included a tapered fiberglass airfoil on a tapered fiberglass spar. The blade was bonded to short steel rod used to cantilever the blade to a stifback. The final visible failure was a bond failure between the fiberglass blade and the steel connecting rod. A hydraulic actuator was used to fatigue the specimen at $1 \mathrm{~Hz}$.

The fatigue test of the blade was periodically stopped to allow modal testing to be performed. The hydraulic actuator was removed and impact excitation with a three pound instrumented mallet was used for the modal tests. Accelerometers were placed at 30 locations on the 32 foot long blade and data was acquired to $64 \mathrm{~Hz}$. Approximately eleven modal frequencies are consistently present in this band. National Renewable Energy Laboratory personnel performed the modal tests using Sandia Lab equipment and consulting. There were 51 days of testing and 32 modal tests spread over a four month period.

The test data included some unexpected phenomena. Following an initial drastic drop in all modal frequencies, most of the modal frequencies stayed constant until failure. At failure, most of the frequencies increased. The static stiffness also seemed to increase. One would expect the stiffness and therefore the frequencies to decrease with damage. An explanation for these phenomena has not been found at this writing. However, the test fixture was reoriented and hydraulic actuators changed at least three times during the test. Also during the four months of testing, a broad range of environmental changes were seen. These changes may have contributed to the unexplained phenomena seen in the data.

\section{STRECH}

The STRECH approach was applied to this data to determine the global extent of damage and to localize 
the data. The data set included a series of thirteen accelerometer locations along the center line of the test item. All sensors measured motion in the most flexible direction. Additional sensors were placed at the root to monitor that most critical area. The chosen load path treated the blade as a simple cantilever beam. Therefore only sensors along the centerline were used and each was assumed connected to its nearest neighbor. Along the blade, rotations were estimated by the parabolic fit approach. At the root, sensors were provided above and below the shaft in the axial direction. This allowed rotations at the root to be estimated by differencing two sensors. The eleven modes were used to calculate the static flexibility shape, which was used in analyzing this data set.

Figure 1 provides the global damage indicator calculated using SRs estimated from translation sensors only. The reader should realize that only 13 tests $(1,3,4,5,6,10,15,20,25,29,30,31$, and 32) have been analyzed to date. It can be seen that a sharp drop occurs between test 10 and test 15 . Work is underway to attempt to correlate the large variations in this factor to changes in the test set-up.

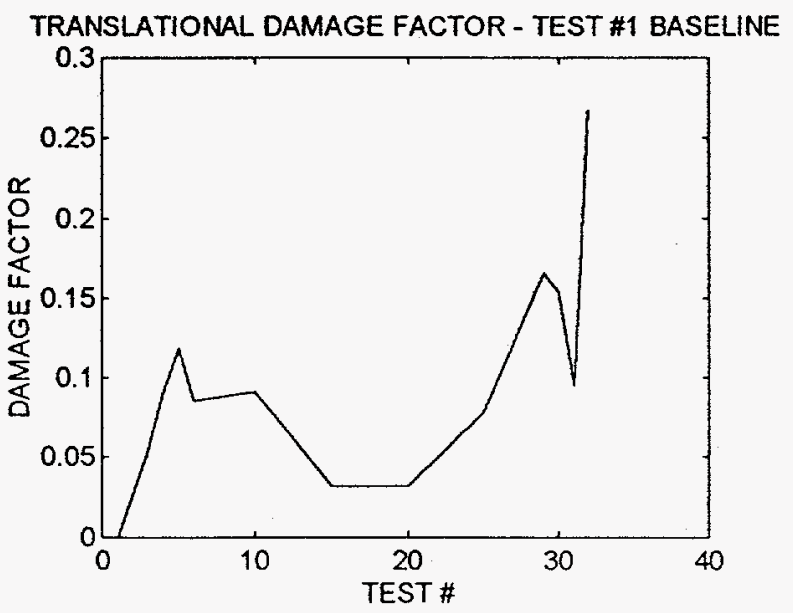

Figure 1. Damage Factor Using Actual Input Location

Figure 2 provides the same translational damage factor, however the static shape calculations usc a sensor location near the root of the blade (and near the failure point) as the simulated input. The data is much more consistent, due to the lack of extreme local variations, than that shown in the previous plot. In fact, after test 15 the trend is as would be expected which is constantly increasing until final failure. However, the initial rise and steep drop after test 10 is still present in the data. The sharp rise between test 1 and test 3 is a result of the initial changes that caused the frequencies to drop. As with the previous data, further study is needed to attempt to explain the characteristics of the data in terms of identifiable changes in the test set-up. Also since the input location was moved to the known damage location, this analysis would require a certain amount of engineering insight to use in a field application.

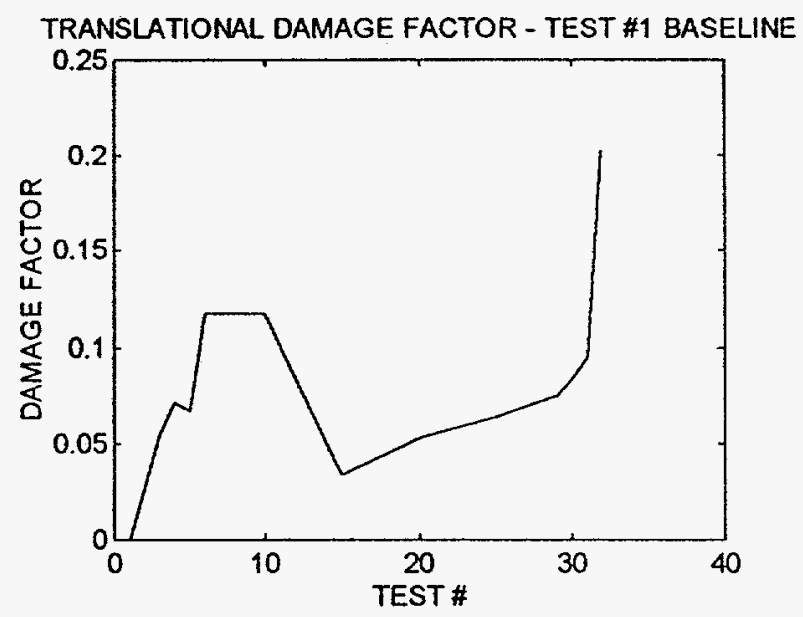

\section{Figure 2. Damage Factor Using Simulated Root Input}

\section{MAXCON}

The MAXCON analysis utilized the same beamlike load path as used in STRECH. Translations and rotations calculated as with STRECH were also used. Scaling (as described in equation (6)) was found to be unnecessary and in fact detrimental. The mass/stiffness separation as described in equation (11) was found to be necessary to achieve success.

Disassembly, as described in equation (12), has not been attempted to date. All eleven modes were used in the analyses presented herein.

Figure 3 provides the absolute values of the first singular vector for both the mass and the stiffness parts of the dynamic residual using test 1 as the undamaged case and test 3 as the damaged case. Therefore, these plots reflect the changes which causeci the initial drop in modal frequencies. It should be noted that there are thirteen sensor locations used in this analysis. Each location has a measured translational and a calculated rotational Degree Of Freedom (DOF). In Figure 3, the odd-numbered DOF's are translations. The rotational DOF's are even-numbered in Figure 3. The cantilever is at DOF's 25 and 26. The final visible damage is between DOF's 19 and 24 as shown in the stifness 
plot marked BK. Hence, this plot shows an initial stiffness change in the expected failure region and at the cantilever. The plots also show large mass changes at several locations closer to the free end of the beam. Since no significant mass changes are expected, they might be associated with errors in the model due to the matrix completion procedure. Constraining the mass matrix completion to maintain the known mass quantities might alleviate some of these discrepencies.
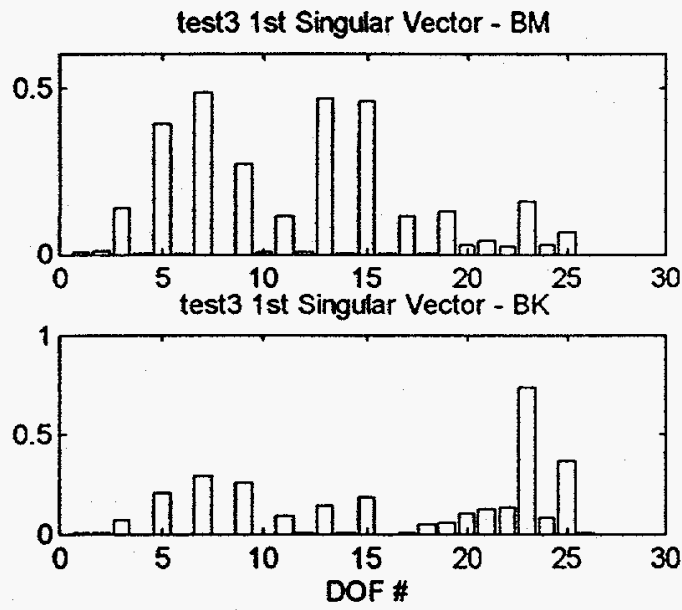

Figure 3. Test 1 To Test 3 Damage Localization

Figure 4 provides the same damage localization analysis as Figure 3. However, the undamaged or baseline test is Test 3 and the damaged or comparison test is Test 32. The stiffness changes are shown to be at DOF's 21 and 23. This is the final failure area. It should be noted that this is the region of highest stiffness in the structure and hence the most sensitivity to stiffness changes and/or noise. However, the mass changes also show large changes at the same locations.
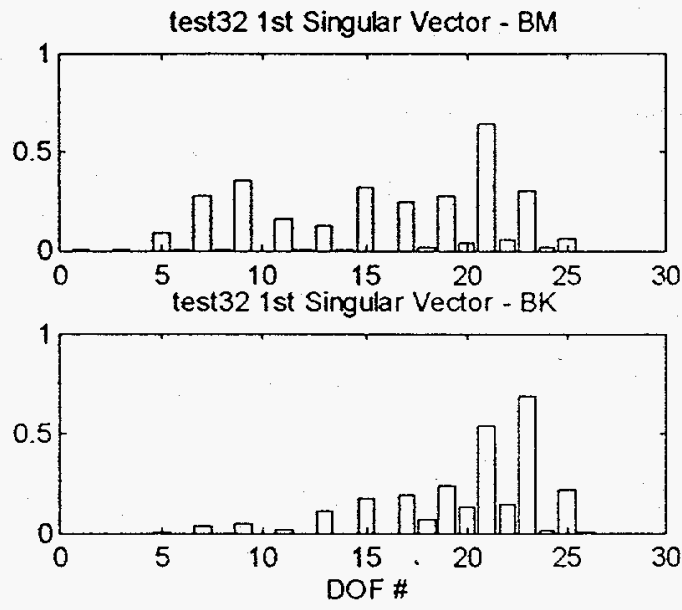

Figure 4. Test 3 To Test 32 Damage Localization
Complete analysis of this test series will require a more complete understanding of the test procedures and any test anomalies which may have occurred during the experiments. However, the results for damage detection from this structure are encouraging. The next section will apply STRECH and MAXCON to an induced damage test of a highway bridge.

\section{Bridge Test}

The Interstate 40 bridge over the Rio Grande in Albuquerque, New Mexico was a fracture critical bridge which means it was constructed without structural redundancy. Figure 5 provides a schematic of this structure. The primary structural members were two 10' deep plate girders which ran the length of the bridge. If one of these members failed, the bridge could be expected to collapse. Since many similar bridges are still in operation, the Federal Highway Administration and the National Science Foundation provided funds to New Mexico State University (NMSU) to develop and test new nondestructive inspection techniques. NMSU was supported by both Los Alamos [19] and Sandia National Laboratories [15] as well as Texas A\&M University [23]. All three support institutions have performed some form of

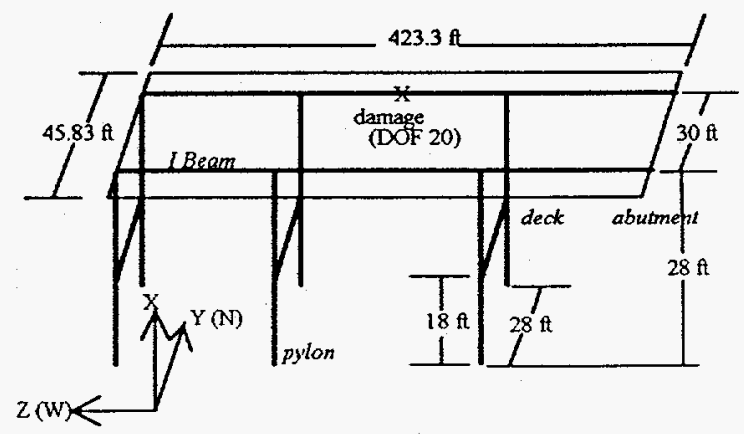

damage detection on the data $[18,19,23]$.

Figure 5. Rio Grande/140 Bridge Schematic

\section{Description of Test}

The Rio Grande/I40 bridge tests were a set of induced damage tests performed on the decommissioned structure. Before demolition of the bridge, a series of progressively more serious cuts were made in one support beam of the bridge [19]. Los Alamos performed a series of modal tests on the bridge as well as extensive modeling. Modal tests were performed in the initial condition and after each cut. Los Alamos personnel also applied the Sandiadeveloped Natural Excitation Technique (NExT) [24] to the bridge data which allowed extraction of moda! 
parameters during traffic excitation. A new type of non-contact sensor based on microwave interferometry was also used on the bridge by Los Alamos personnel. Sandia designed and operated the exciter system for the dynamics tests. Sandia personinel also acted as consultants for the application of NExT and provided some logistics support during the modal tests.

A series of four cuts were made in the plate girder after the bridge was closed to all traffic. The fourth cut completely severed the lower half of the plate girder I section. Random excitation was provided from 2-12 $\mathrm{Hz}$ with a peak input of 2,000 lbs. Uniaxial sensors at 26 locations were used as the primary instrumentation set. All sensors and the force input were in the vertical direction. Six vertical modes were extracted. Power spectral density data from 10 additional sensor locations for the Texas A\&M work were also acquired. Also, stepped sine testing was provided for the Los Alamos microwave sensors.

Table 1 lists the modal frequencies for the first six modes after each cut. Notice the slight increase in frequency after the first cut. This inconsistency is believed to be due to mass being removed from an adjacent bridge which shares the same pylon. However, analysis using MAXCON points to a major change at only one side of the bridge, and has tended to point to a stiffness change. In general the changes in frequency become obvious only after the fourth cut.

Table 1. Modal Frequencies vs. Damage Case

\section{DAMAGE CASE}

$\begin{array}{clcccc}\begin{array}{c}\text { MODE } \\ \text { (Hz) }\end{array} & 0 & 1 & 2 & 3 & 4 \\ 1 & 2.48 & 2.51 & 2.52 & 2.46 & 2.29 \\ 2 & 2.96 & 2.99 & 2.99 & 2.94 & 2.84 \\ 3 & 3.54 & 3.57 & 3.52 & 3.48 & 3.49 \\ 4 & 4.09 & 4.12 & 4.10 & 4.04 & 3.99 \\ 5 & 4.16 & 4.21 & 4.19 & 4.14 & 4.15 \\ 6 & 4.64 & 4.67 & 4.66 & 4.58 & 4.52\end{array}$

\section{STRECH}

The most successful STRECH calculations used static flexibility and estimated rotations. The first extraction of undamaged modal parameters was used as the baseline for the STRECH calculations. The results for the global indicator are printed in Table 2. The first two rows are the damage indicators for the undamaged bridge where the same data was used, but different modal extraction techniques were utilized to form the static flexibility. Then the damage indicators are calculated for each cut. Although this is not a statistically conclusive study, it appears that the damage indicator begins to rise significantly enough at cut 2 to indicate the presence of damage.

Table 2 - Damage Indicators

\begin{tabular}{|l|c|}
\hline \multicolumn{1}{|c|}{ Case } & $\begin{array}{c}\text { Damage } \\
\text { Indicator }\end{array}$ \\
\hline Undamaged - Extraction 2 & $9 \%$ \\
\hline Undamaged - Extraction 3 & $8 \%$ \\
\hline Cut 1 & $14 \%$ \\
\hline Cut 2 & $28 \%$ \\
\hline Cut 3 & $40 \%$ \\
\hline Cut 4 & $33 \%$ \\
\hline
\end{tabular}

For the damage localization calculations, a minimum denominator value of only one percent (of the maximum rotation difference in the undamaged case) was used to filter the most noisy calculations. The location of damage was correctly identified for the two worst damage cases, cuts 3 and 4 . For cut 1 the damaged location was the second choice of the algorithm. For cut 2 the damaged location was the fourth choice. The fidelity of the cut 1 data was higher than for cut 2 . This would provide a better signal to noise ratio in the FRFs which could lead to a more accurate static flexibility shape for cut 1 than for cut 2 . Even though the signal to noise ratio might not have been as good for cut 4 , the damage was so significant that the noise did not matter so much. Note that the $S R$ increases with increasing level of damage in the actual damaged element (number 107-108). Table 2 lists the results.

Table 2 - Predicted Damage Locations for Static Flexibility

\begin{tabular}{|c|c|c|}
\hline Case/Element No. & $\begin{array}{c}\text { STRECH } \\
\text { Ratio }\end{array}$ & Comment \\
\hline Cut 4/ Element 107-108 & 13.2 & Correct 1st choice \\
\hline Cut 3/ Element 107-108 & 10.5 & Correct 1st choice \\
\hline Cut $2 /$ Element $4-5$ & 7.07 & Wrong 1st choice \\
\hline Cut $2 /$ Element $10-11$ & 2.95 & Wrong 2 nd choice \\
\hline Cut $2 /$ Element $12-13$ & 2.89 & Wrong 3rd choice \\
\hline Cut $2 /$ Element 107-108 & 2.81 & Correct 4th choice \\
\hline Cut $1 /$ Element 4-5 & 4.18 & Wrong 1st choice \\
\hline Cut $1 /$ Element 107-108 & 2.53 & Correct 2nd choice \\
\hline
\end{tabular}


west. Elements 101-102 through 112-113 were on the damaged north side of the bridge moving from east to west.

\section{MAXCON}

For the MAXCON analysis both rotations and translations were used. The load paths were defined assuming simple springs connected each sensor to its nearest neighbors. This included the sensors directly and diagonally across the bridge. The rotations and translations were connected as one could expect from beam-type elements. Additional springs to ground were also assumed. It was not useful to separate mass and stiffness properties as seen in equation (11). However, to obtain successful results the model had to be separated to allow changes only in the assumed model form as described in equation (12). Scaling, as described by equation (6) was also required.

Figure 6 provides a bar chart of the entries in the first singular vector of the scaled B matrix which is the dynamic residual associated with the assumed model. This data set was calculated using the undamaged data set as the baseline and cut_l as the comparison case. Note that there are 26 translation DOF's with 13 on each side of the bridge. These are the odd-numbered DOF's. The 26 rotations are the even-numbered DOF's. The expected damage location is between DOF 39 and DOF 42. This data shows the largest indication of damage at DOF 39 with large changes at DOF 37 and DOF 41. Also another large indication of damage is seen at the end of the bridge at DOF 51 . This may be indicative of the changes that caused the modal frequencies to increase after the first cut.

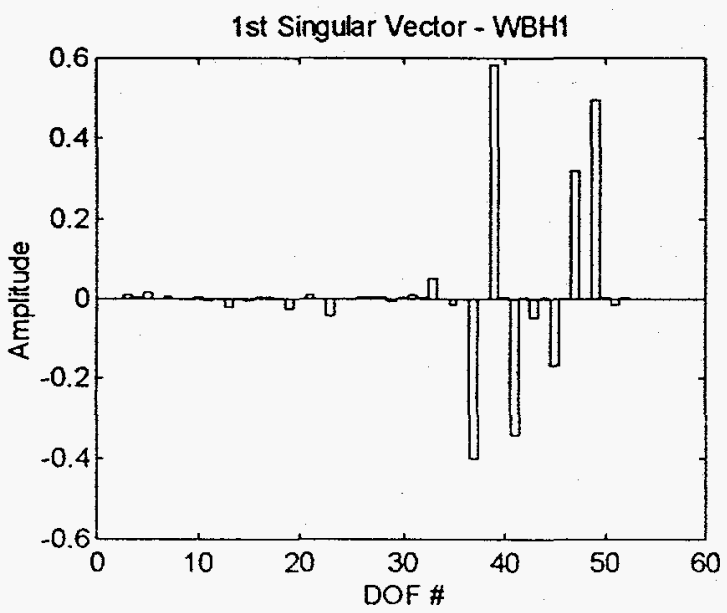

Figure 6. Pristine To Cut 1 Damage Localization

Figure 7 provides the same information for cut 2 with similar results as seen in Figure 6 . Figure 8 provides the information for cut 3 , again with similar results. And finally, Figure 9 provides the cut 4 data. One can see that the known damage location (DOF 39) is starting to increase relative to the phenomena at the end of the span.

\section{SUMMARY AND CONCLUSIONS}

Initial studies on damage detection and health monitoring have been performed using two techniques for damage localization. These techniques have been applied to two operational structures: a HAWT blade undergoing a fatigue test and a bridge undergoing an induced damage test. The STRECH algorithm provides a damage localization as well as a global damage indicator. It works best on static data, which may include static flexibility shapes estimated from dynamic mode shapes or the first mode of simple systems. The global indicator is fairly consistent, however more work needs to be performed to define a noise floor consistently. The MAXCON approach appears to be more robust for damage localization, but does not include a global indicator. Several measurable physical quantities are available to act as further constraints during completion of the matrices. Also, choosing the scaling on the null space to simultaneously zero the expected entries in the mass and stiffness matrices would be a much more desirable approach.

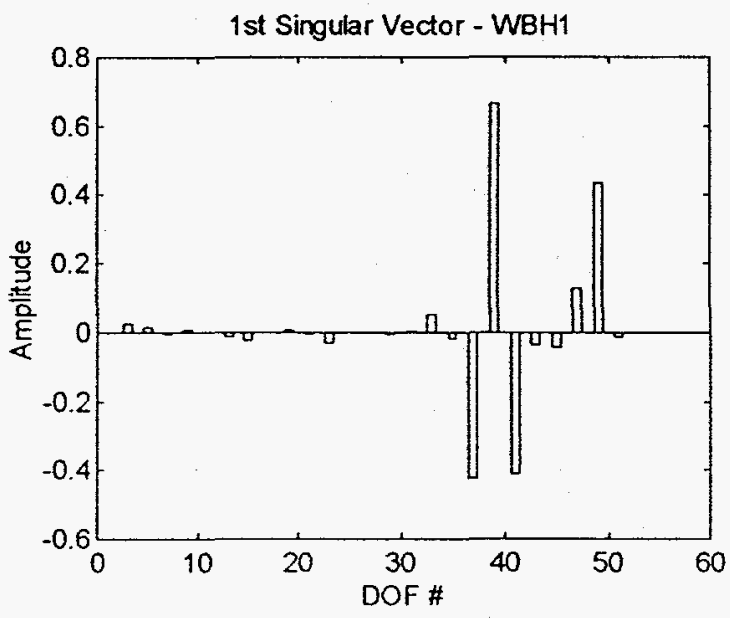

Figure 7. Pristine To Cut 2 Damage Localization

\section{ACKNOWLEDGMENTS}

Our appreciation goes out to Chuck Farrar at Los Alamos National Labs and the Civil Engineering Department of New Mexico State University for allowing us to participate in the 140 bridge test. 
Engineers at the National Renewable Energy Lab were largely responsible for performing the wind turbine blade modal tests. The authors also wish to thank Lee Peterson, K.C. Park, and Scott Doebling of the University of Colorado at Boulder; David Zimmerman of the University of Houston; and Ken Alvin, Garth Reese, Bruce Hansche, Ron Rodeman, Dennis Roach, and Paul Veers of Sandia National Laboratories for their collaboration and insight. This work was supported by the United States Department of Energy under Contract DE-AC04-94AL85000.

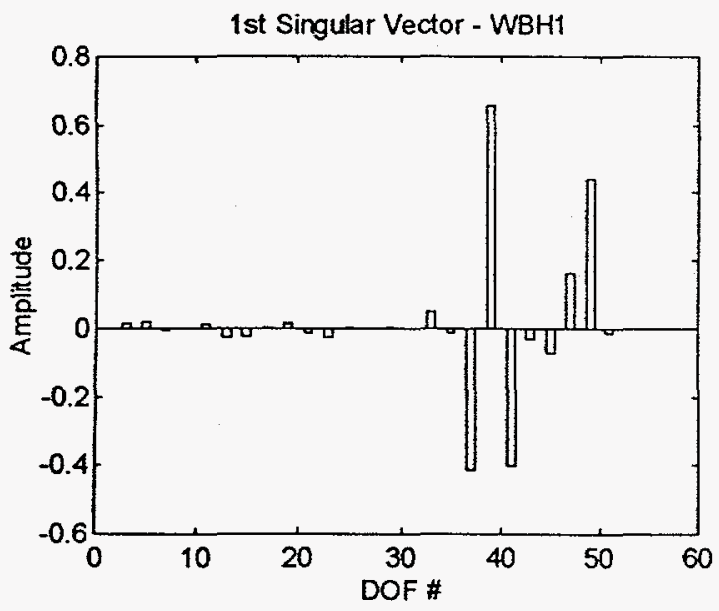

Figure 8. Pristine To Cut 3 Damage Localization

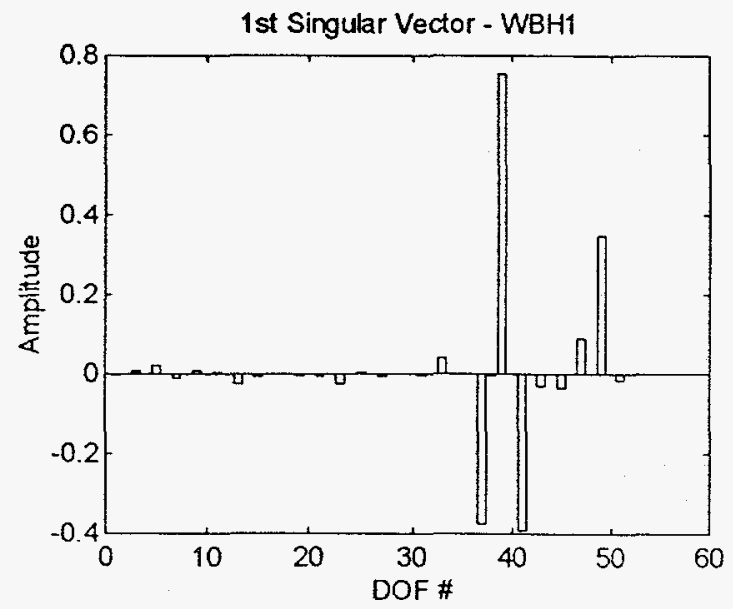

Figure 9. Pristine To Cut 4 Damage Localization

\section{REFERENCES}

1. Zimmerman, D. C. and Widengren, M., "Correcting Finite Element Models Using a Symmetric Eigenstructure Assignment
Technique", AIAA Journal, Vol. 28, No. 9 , September 1990, pp. 1670-1676.

2. Zimmerman, D. C. and Kaouk, "An Eigenstructure Assignment Approach For Structural Damage Detection", AIAA Journal, Vol. 30, No. 7, July 1992, pp. 1848-1857.

3. Kaouk, Mohamed and Zimmerman, David C., "Structural Damage Assessment Using a Generalized Minimum Rank Pertubation Theory", AIAA-93-1483-CP, presented at the 34th Structures, Structural Dynamics, and Materials Conference, La Jolla, CA, April, 1993.

4. Kaouk, Mohamed and Zimmerman, David C., "Structural Damage Detection Using Measured Modal Data and No Original Analytical Model", presented at the 12th International Modal Analysis Conference, Honolulu, Hawaii, January 31 - February 3, 1994.

5. Zimmerman, David C. and Simmermacher, Todd, "Model Refinement and System Health Monitoring Using Data From Multiple Static Loads and Vibration Tests", AIAA-94-1714-CP, presented at the AIAA SDM Dynamics Specialists Conference, Hilton Head, SC, April 21-22, 1994.

6. Zimmerman, D. C., Smith, S. W., Kim, H. M., and Bartkowicz, T. J., "An Experimental Study of Structural Damage Detection Using Incomplete Measurements", AIAA-94-1712-CP, presented at the AIAA SDM Dynamics Specialists Conference, Hilton Head, SC, April 21-22, 1994.

7. Simmermacher, T. W., Zimmerman, D. C., Mayes, R. L., Reese, G. M., and James, G. J., "The Effects of Finite Element Grid Density on Model Correlation and Damage Detection of a Bridge", paper AIAA 95-1072, to be presented at the AIAA Adaptive Structures Forum, New Orleans, LA, April 13-14, 1995.

8. Doebling, S. W.; Hemez, F. M.; Barlow, M. S. Peterson, L. D.; and Farhat, C., "Damage Detection in a Suspended Scale Model via Model Update", proceedings of the 11th IMAC conference, Kissimmee Florida, February 1-4, 1993 
9. Doebling, S. W.; Hemez, F. M.; Barlow, M. S.; Peterson, L. D.; and Farhat, C., "Selection of Experimental Modal Data Sets for Damage Detection via Model Update", paper AIAA-931481-CP, proceedings of the 34th SDM conference, La Jolla, CA, April 1993.

10. Alvin, Kenneth F., "Second-Order Structural Identification Via State Space-Based System Realizations," CU-CSSC-93-09, Center for Space Structures and Controls, University of Colorado, Boulder, Colorado, April 1993.

11. Alvin, K. F.; Peterson, L. D.; and Park, K. C., "A Method for Determining Minimum-Order Mass and Stiffness Matrices from Modal Test Data", AlAA Journal, Vol. 33, No.1, pp. 128$135,1995$.

12. Peterson, L. D.; Alvin, K. F.; Doebling, S. W.; and Park, K. C., "Damage Detection Using Experimentally Measured Mass and Stiffness Matrices", paper AIAA-93-1482-CP, proceedings of the 34th SDM conference, La Jolla, CA, April 1993.

13. Doebling, Scott W., Alvin, Kenneth F., and Peterson, Lee D., "Limitations of State-Space System Identification Algorithms for Structures with High Modal Density", presented at the 12th International Modal Analysis Conference, Honolulu, HI, January 31 - February 3, 1994.

14. Mayes, Randy L., "Error Localization Using Mode Shapes - An Application to a Two Link Robot Arm", presented at the 10th International modal Analysis Conference, San Diego, CA, February 3-7, 1992.

15. Mayes, Randy L. and Nusser, Michael A., "The Interstate-40 Bridge Shaker Project", SAND 940228, Sandia National Laboratories, Albuquerque, NM, April 1994.

16. Hansche, B., James, G., Pride, N., Roach, D., Schmidt, T., and Webster, J., "Initial Studies on the Use of Laser Velocimetry, in the Inspection and Health Monitoring of Aircraft", Proceedings of the Quantitative Nondestructive Evaluation Conference", Snowmass, CO, August 2, 1994.

17. James, G., Mayes, R, Carne, T., and Reese, G., "Damage Detection and Health Monitoring of Operational Structures", AD-Vol. 45. MD-Vol.
54, Adaptive Structures and Composite Materials: Analysis and Application, Edited by E. Garcia, H. Cudney, and A. Dasgupta, ASME, presented at the 1994 ASME Winter Annual Meeting, Chicago, IL, November 6-11, 1994.

18. Mayes, Randall L., "An Experimental Algorithm for Detecting Damage Applied to the I-40 Bridge Over the Rio Grande", presented at the $13^{\text {th }}$ International Modal Analysis Conference, Nashville, TN, February 13-16, 1995.

19. Farrar, C. R., Baker, W. E., Bell, T. M., Cone, K. M., Darling, T. W., Duffey, T. A., Eklund, A., and Migliori, A., "Dynamic Characterization and Damage Detection in the I-40 Bridge over the Rio Grande", LA-12767-MS, Los Alamos National Labs, Los Alamos, NM, June 1994.

20. Doebling, Scott, "Report on Development of a Laser Doppler Velocimeter System", final report for Outstanding Student Summer Program at Sandia National Laboratories, Experimental Structural Dynamics Department, August 1993.

21. Doebling, S., Alvin, K., and Peterson, L., "Improved Convergence of Estimated Stiffness Parameters for Experiments with Incomplete Reciprocity", to be presented at the 1995 Structures, Structural Dynamics, and Materials Conference, New Orleans, LA, April, 1995.

22. Peterson, L., Alvin, K., and Doebling, S., "Experimental Determination of Local Structural Stiffness by Disassembly of Measured Stiffness Matrices", to be presented at the 1995 Structures, Structural Dynamics, and Materials Conference, New Orleans, LA, April, 1995.

23. Subbs, Norris, Kim, Jeont-Tae, and Farrar, Charles, "Field Verification of a Nondestructive Damage Localization and Severity Estimation Algorithm", presented at the $13^{\text {th }}$ International Modal Analysis Conference, Nashville, TN, February 13-16,1995.

24. James, George H., Carne, Thomas G., and Lauffer, James P., "The Natural Excitation Technique (NExT) for Modal Parameter Extraction from Operating Wind Turbines", SAND92-1666, Sandia National Laboratories, Albuquerque, NM, 1993. 